\title{
Association of Plasma Lipids Fatty Acid Composition With Metabolic Profile of Czech Adolescents
}

\author{
P. HLAVATY ${ }^{1,2}$, E. TVRZICKA ${ }^{3}$, B. STANKOVA ${ }^{3}$, H. ZAMRAZILOVA ${ }^{1}$, \\ B. SEDLACKOVA ${ }^{1}$, L. DUSATKOVA ${ }^{1}$, V. HAINER $^{1}$, M. KUNESOVA ${ }^{1}$
}

${ }^{1}$ Institute of Endocrinology, Prague, Czech Republic, ${ }^{2} \mathrm{OB}$ Clinic, Prague, Czech Republic, ${ }^{3}$ Fourth Department of Internal Medicine, First Faculty of Medicine, Charles University in Prague and General University Hospital, Prague, Czech Republic

Received July 16, 2015

Accepted July 30, 2015

\section{Summary}

Obesity in childhood increases the risk of obesity in adulthood and is predictive for the development of metabolic disorders. The fatty acid composition is associated with obesity and obesityassociated disorders. We investigated the relationship between serum fatty acids composition, adiposity, lipids profile, parameters of glucose metabolism and leptin. The study subjects were 380 adolescents aged 15.0-17.9 years. The study's variables included anthropometric measurements, levels of serum lipids and hormonal parameters. Individual fatty acids were determined in plasma by gas-liquid chromatography. Palmitoleic acid (16:1n-7, PA) significantly positively correlated with percentage of body fat. Saturated fatty acids in phospholipids (PL) positively correlated with BMI and percentage of body fat. PA content in all lipids classes positively correlated with total cholesterol (TC), HDL cholesterol, triglycerides (TG) levels. Stearoyl-CoA desaturase (SCD) activity positively correlated with percentage of body fat and positive correlations of SCD and PA level with leptin were found. Plasma PA content and SCD are associated with adiposity and leptin in obese adolescents. No significant correlation between PA level and insulin resistance was found. Palmitoleate positively correlated with TC, HDL cholesterol, TG and LDL cholesterol levels.

\section{Key words}

Obesity • Adolescents • Fatty acids • Palmitoleic acid • StearoylCoA desaturase $\bullet$ Leptin

\section{Corresponding author}

P. Hlavaty, Obesity Management Center, Institute of Endocrinology, Narodni 8, CZ-116 94 Prague, Czech Republic. Fax: +420224905325. E-mail: phlavaty@endo.cz

\section{Introduction}

Obesity is characterized by an imbalance between energy intake and expenditure, resulting in an increase of body fat storage. Visceral obesity plays an important role in the development of metabolic syndrome (Moller and Kaufman 2005).

Fatty acid composition in adipose tissue is affected by a dietary intake of fatty acids and processing of fat (lipolysis and endogenous lipogenesis). The fatty acid composition in serum phospholipids (PL) influences several important physiological functions related to the development of the metabolic syndrome components obesity, insulin sensitivity and the risk of type 2 diabetes (Huang et al. 2010, Pelikanova et al. 2001, Vessby et al. 1994, Zak et al. 2007). Some studies have also shown a relationship between individual saturated fatty acids (SAFA), insulin sensitivity (Iggman et al. 2010) and adiposity indexes (Kunesova et al. 2002a,b).

Palmitoleic acid (16:1n-7, PA) is an important product of the endogenous lipogenesis and is one of the main monounsaturated fatty acids (MUFA). In rats, levels of PA and oleic acid (18:1n-9) were increased after a sucrose diet. Moreover, plasma glucose, insulin, and triglyceride (TG) levels were also significantly higher (Fukuchi et al. 2004).

The results from studies suggest that PA in serum cholesterol esters (CE) may be a metabolic indicator reflecting endogenous lipogenesis (Kunesova et al. 2002a,b). Conversely, the level of PA in serum free fatty acids is a strong predictor of insulin sensitivity in individuals with an increased risk of type 2 diabetes 
(Stefan et al. 2010).

PA is a product of desaturation of palmitic acid (16:0) by stearoyl-CoA desaturase (SCD). SCD enzymes are involved in the de novo synthesis of MUFA from SAFA (Miyazaki and Ntambi 2003). SCD activity and PA level may be positively associated with obesity and elevated accumulation of abdominal fat in humans (Attie et al. 2002, Paillard et al. 2008).

Overall, results indicate that changes in the MUFA composition and activity of SCD may significantly contribute to the development of obesity and metabolic syndrome. The aim of the presented study was to investigate the relationship between serum lipids fatty acids composition, adiposity, lipids profile, parameters of glucose metabolism and leptin in Czech adolescents.

\section{Subjects and Methods}

\section{Subjects}

The participants in this study were from the Childhood Obesity Prevalence And Treatment (COPAT) project. The analyses were performed on 380 Czech adolescents aged 15.0-17.9 years from a general population including all body weight categories. The basic and anthropometric characteristics of the study cohort are shown in Table 1. The mean age was $16.4 \pm 0.9$ years and the mean BMI was $22.34 \pm 4.0 \mathrm{~kg} / \mathrm{m}^{2}$.

A detailed design of the project has already been described (Aldhoon-Hainerova et al. 2014). All subjects and their parent(s) provided written informed consent to the participation in the study. The study protocol was approved by the Ethical Committee of the Institute of Endocrinology in Prague.

Table 1. Basic and anthropometrical characteristics of the study cohort.

\begin{tabular}{ll}
\hline$n$ & 380 \\
Age (years) & $16.4 \pm 0.9$ \\
Weight $(\mathrm{kg})$ & $66.2 \pm 14.4$ \\
BMI $\left(\mathrm{kg} / \mathrm{m}^{2}\right)$ & $22.3 \pm 4.0$ \\
Waist circumference (cm) & $80.6 \pm 10.2$ \\
Hip circumference (cm) & $94.7 \pm 8.4$ \\
Fat mass (\%) & $21.4 \pm 7.3$ \\
Fat mass $(\mathrm{kg})$ & $14.6 \pm 7.5$ \\
Lean body mass $(\mathrm{kg})$ & $51.5 \pm 9.8$ \\
\hline
\end{tabular}

Anthropometry and body composition

The percentage of body fat was assessed by a bioelectrical impedance method (Tanita BC-418 MA, Tanita Corporation, Tokyo, Japan). Body mass index was calculated by dividing mass in kilograms by the square of height in meters $\left(\mathrm{kg} / \mathrm{m}^{2}\right)$.

\section{Biochemical and hormonal parameters}

Blood samples were collected from the subjects after they had fasted overnight. Plasma leptin was measured by using an immunoradiometric assay kit (DRG Diagnostics, Germany). Serum total cholesterol (TC), HDL and LDL cholesterol and TG and insulin were measured by an automatic biochemical analyzer (Cobas 6000, Roche Diagnostics GmbH, Germany), insulin resistance was evaluated by the HOMA-IR that was obtained by the following formula: fasting plasma insulin (microunits per liter) $\mathrm{x}$ fasting glucose (millimoles per liter)/22.5 (Matthews et al. 1985).

\section{Lipid extraction and fatty acid composition}

Total lipid was extracted from $1 \mathrm{ml}$ of plasma by the method of Folch and coworkers (Folch et al. 1957) using dichlormethane instead of chloroform (Carlson 1985). Individual lipid classes (CE, TG and PL), were separated by TLC with the mobile phase heptane-diethylether-acetic acid (80:20:1, v/v/v). Separated lipid classes were transmethylated to FAME with $1 \mathrm{M}$ sodium methoxide in dry methanol under nitrogen atmosphere in darkness without previous separation from the layer material. Samples of TG and PL reacted for $60 \mathrm{~min}$ at ambient temperature, those of $\mathrm{CE}$ $20 \mathrm{~min}$ at $80^{\circ} \mathrm{C}$. The reaction mixture was neutralized with $1 \mathrm{M}$ aceticacid, methyl esters were extracted twice into hexane and passed through the column $(5 \times 20 \mathrm{~mm})$ of anhydrous sodium sulphate. The combined extracts were dried under nitrogen, dissolved in an appropriate volume of isooctane and stored at $-20{ }^{\circ} \mathrm{C}$ until analyzed.

Gas chromatography was performed with a Trace GC gas chromatograph combined with AS2000 autosampler (Thermo Finnigan, USA). Chromatograph was equipped with a capillarysplit/splitless injector and flame ionization detector (FID).

Analysis of FAME was performed on the fused-silica capillary column coated with $0.25 \mu \mathrm{m}$ chemically bonded stationary phase Select FAME ( $100 \mathrm{~m}, 0.25 \mathrm{~mm}$ I.D., Agilent Technologies, The Netherlands). The oven temperature was programmed from $80{ }^{\circ} \mathrm{C}$ to $120^{\circ} \mathrm{C}$ at $4 \% \mathrm{~min}$, to $270{ }^{\circ} \mathrm{C}$ at $2 \% / \mathrm{min}$, 


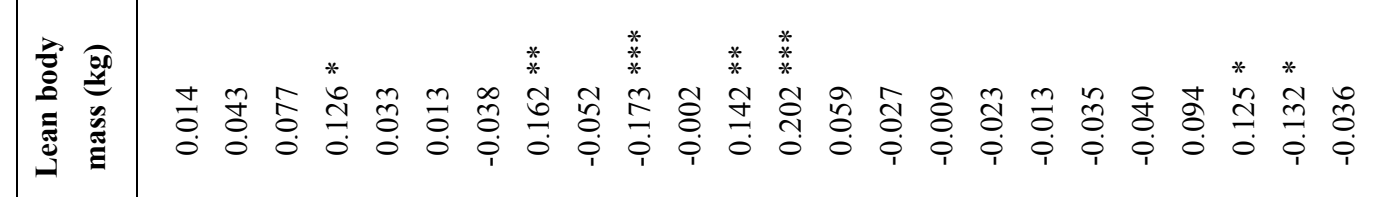

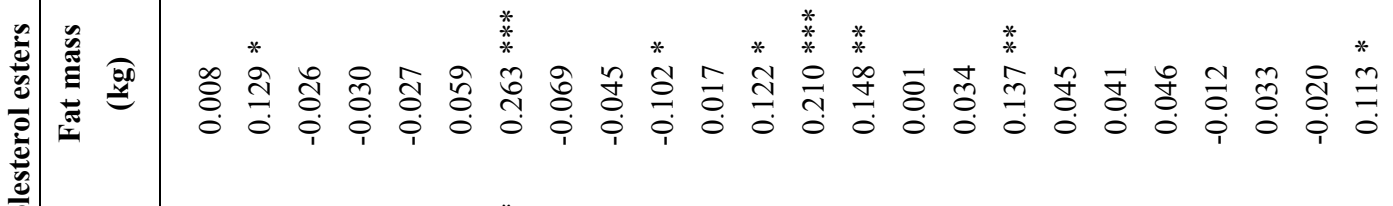

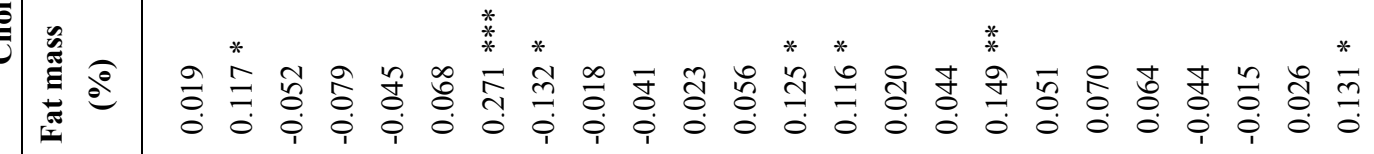

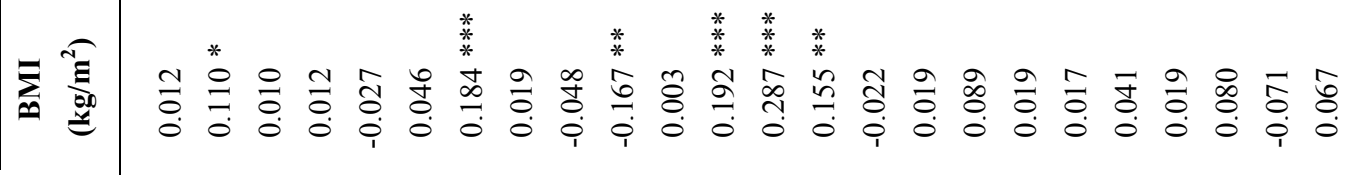

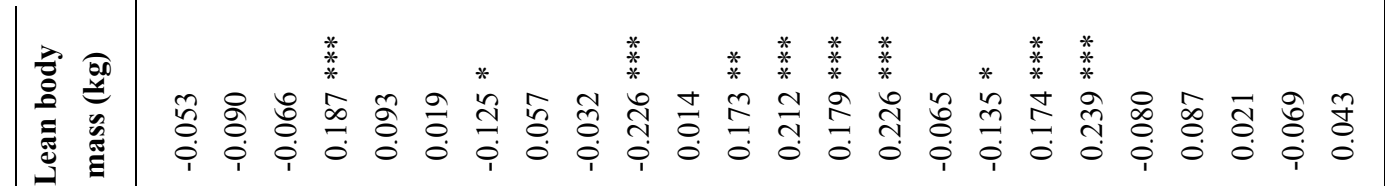

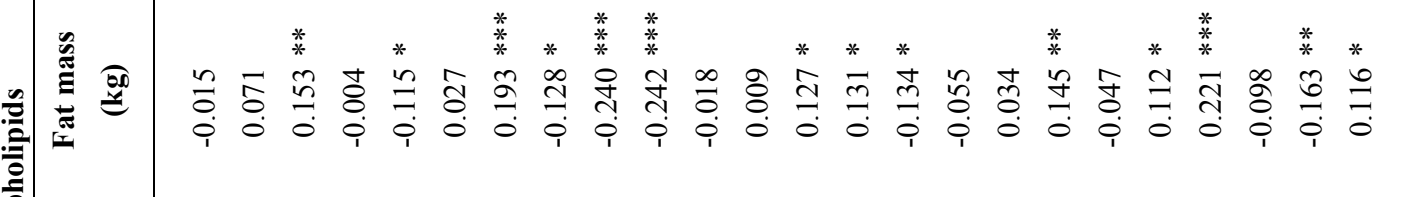

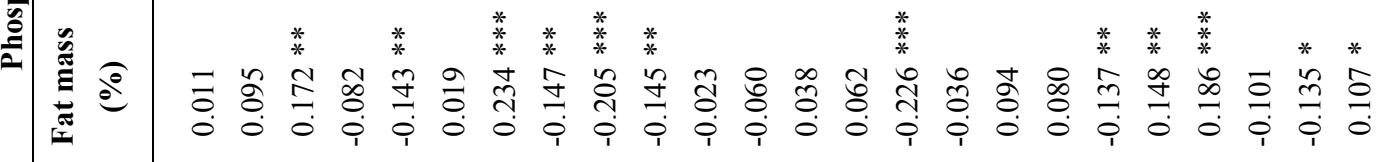

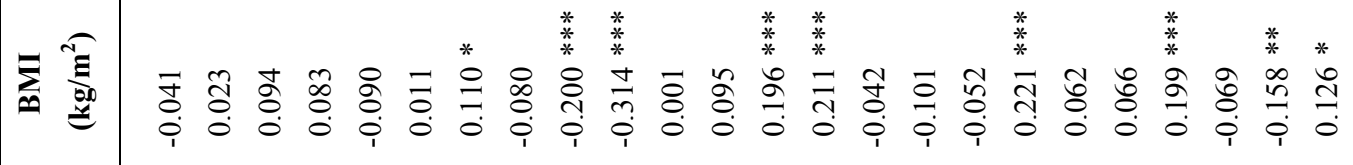

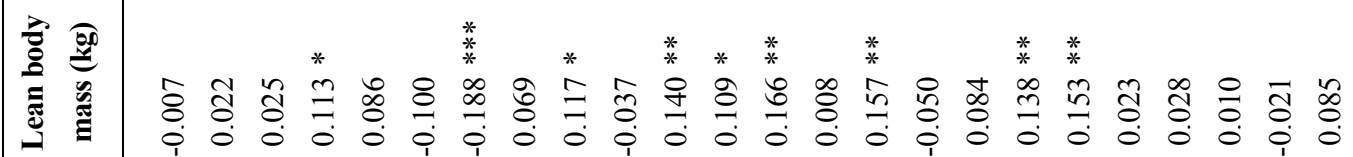

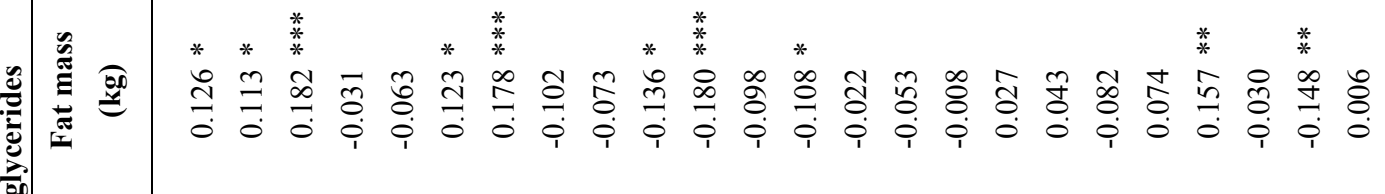

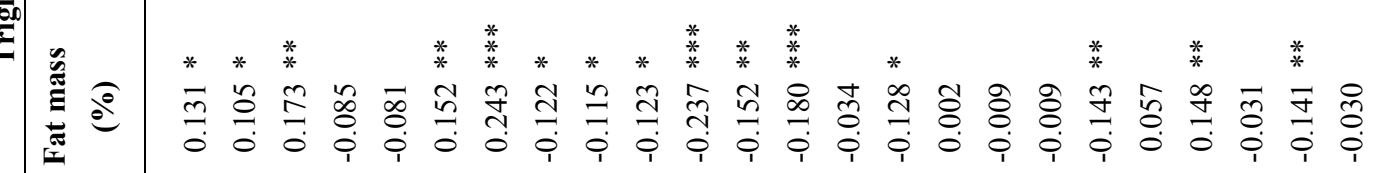

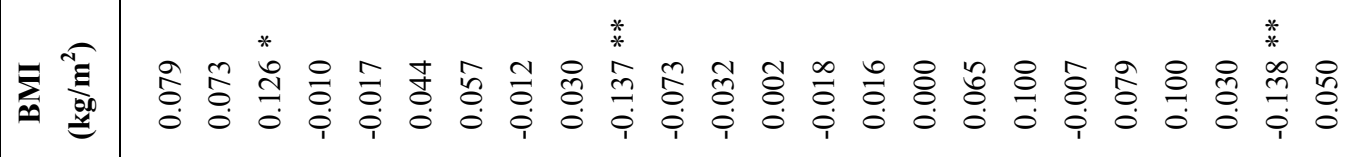

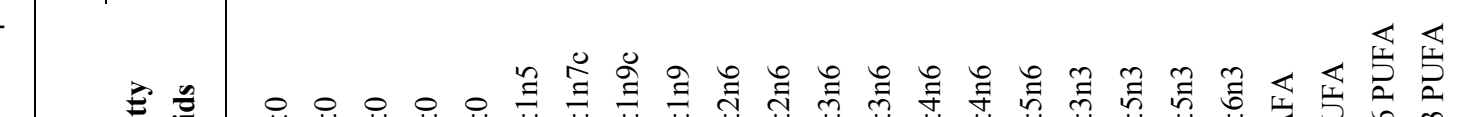

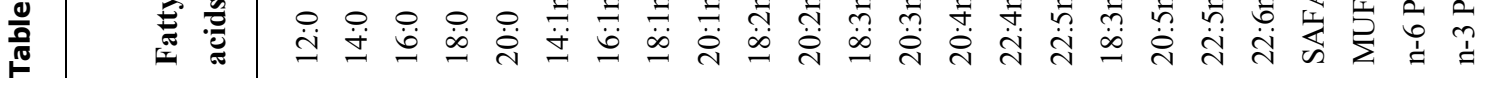




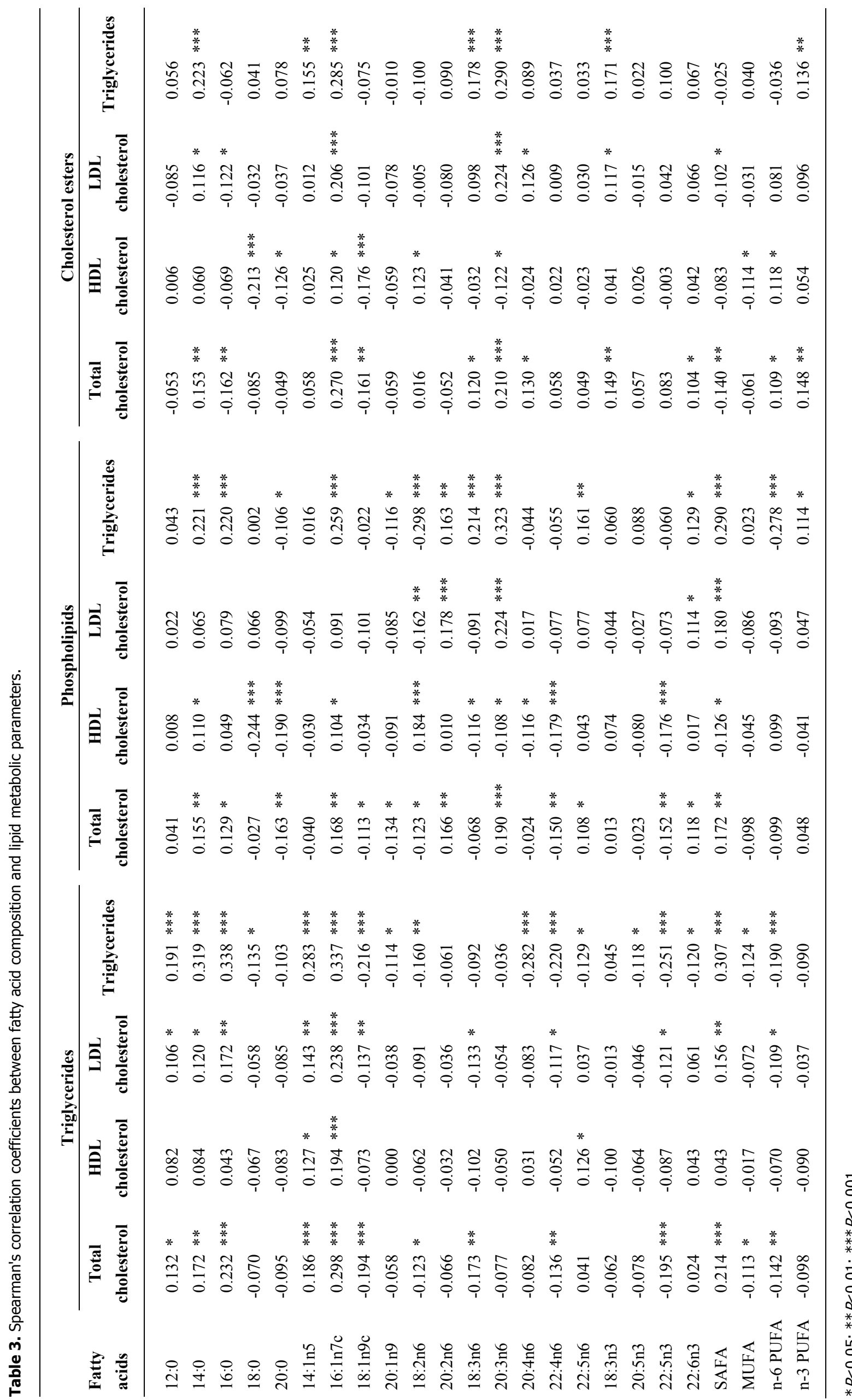




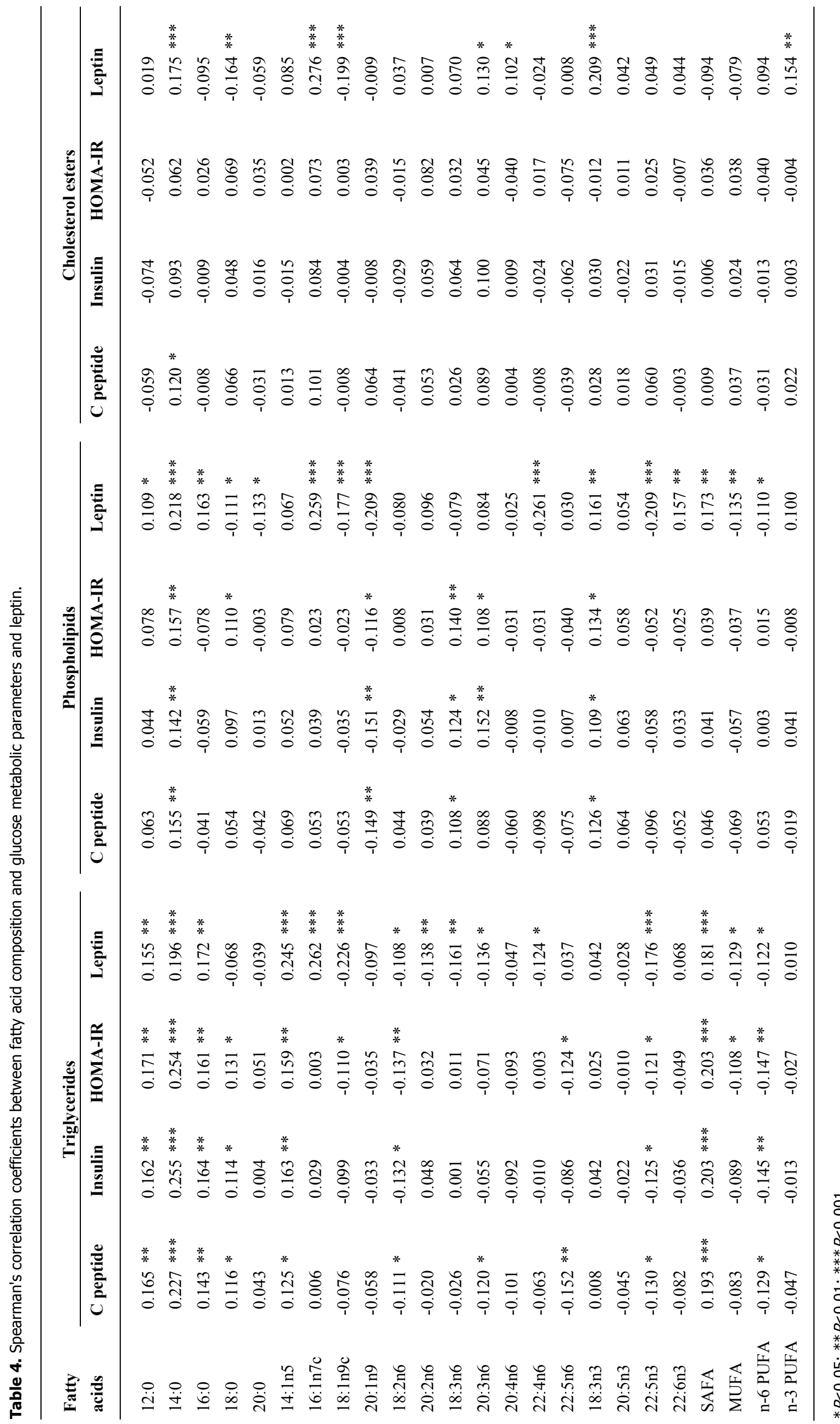


then isothermal $25 \mathrm{~min}$ for PL and TG, and $55 \mathrm{~min}$ for CE. The injector and detector temperatures were 250 and $270{ }^{\circ} \mathrm{C}$, respectively. Hydrogen carrier gas was maintained at a head pressure of $70 \mathrm{kPa}$ and split flow $15 \mathrm{ml} / \mathrm{min}$, splitless time $0.25 \mathrm{~min}$.

Integration software Clarity (Data Apex Ltd. Prague, Czech Republic) was used for data acquisition and handling.

SCD activity can be estimated from the desaturation indices. The product-to-precursor ratio (palmitoleic/palmitic, 16:1n-7/16:0) was used to estimate the activity of stearoyl-CoA desaturase (SCD) (Attie et al. 2002).

\section{Statistical analyses}

All data are expressed as mean \pm standard error of the mean (SEM). The Spearman's correlation coefficient was used to assess the correlation between 2 variables. For all statistical analyses, $\mathrm{P}$ values below 0.05 were used to indicate the statistical significance. The statistical software was Statgraphics Centurion XVI (Statistical Graphics Corp., Rockville, MD, USA).

\section{Results}

Spearman's correlation coefficients between fatty acid composition and anthropometrical parameters are shown in Table 2. PA in plasma TG, PL and CE significantly positively correlated with percentage of body fat. Negative correlation between omega- 6 fatty acids content in plasma TG and PL, and BMI and percentage of body fat were observed while omega-3 fatty acids in PL positively correlated with BMI and percentage of body fat. Linoleic acid (18:2n-6) in all lipid classes had a significant negative correlation with BMI; with percentage of fat mass only in TG and PL. Dihomo- $\gamma$-linoleic acid (20:3n-6, DGLA) in PL positively correlated with BMI and lean body mass. SAFA in PL positively correlated with BMI and percentage of body fat.

Spearman's correlation coefficients between fatty acid composition and lipid metabolic parameters are shown in Table 3. Myristic (14:0) and palmitic (16:0) acids positively correlated with serum TC and TG. PA content in all lipids classes positively correlated with TC, HDL cholesterol, TG levels and LDL cholesterol (except for PA in PL). DGLA in PL and CE positively correlated with TC, HDL and LDL cholesterol and TG.

Spearman's correlation coefficients between fatty acid composition and glucose metabolic parameters and leptin are shown in Table 4. SAFA in TG positively correlated with $\mathrm{C}$ peptide, insulin, HOMA-IR and leptin. PA in all lipid classes positively correlated with leptin.

SCD activity expressed as the ratio 16:1n-7/16:0 had a positive correlation with percentage of body fat and with leptin; correlation with 18:1n-9/18:0 ratio was not significant. However, only the ratio 18:1n-9/18:0 had a significant negative correlation with HOMA-IR (Table 5). We found no statistical difference in SCD activity between adolescents with normal BMI (defined as BMI between the $25^{\text {th }}$ and $75^{\text {th }}$ percentile, according to the age and gender) and obese adolescents with BMI above the $95^{\text {th }}$ percentile (data not shown).

Table 5. Spearman's correlation coefficients between stearoyl$\mathrm{COA}$ desaturase and anthropometric and metabolic parameters.

\begin{tabular}{lcccc}
\hline & \multicolumn{2}{c}{$\mathbf{1 6 : 1 n - 7 / 1 6 : 0}$} & \multicolumn{1}{c}{$\mathbf{1 8 : 1 \mathbf { n } - 9 / 1 8 : 0}$} \\
\cline { 2 - 5 } & $r$ & $p$ & $r$ & $p$ \\
\hline Bodyfat mass (\%) & 0.272 & $<0.0001$ & 0.001 & $\mathrm{NS}$ \\
Leptin & 0.294 & $<0.0001$ & -0.040 & $\mathrm{NS}$ \\
HOMA-IR & 0.048 & $\mathrm{NS}$ & -0.152 & $<0.01$ \\
\hline
\end{tabular}

NS - non-significant.

\section{Discussion}

Our results show significant relation of plasma PA content with higher percentage of body fat mass. Several studies in obese adults and children already reported similar findings (Gong et al. 2011, Kunesova et al. 2002b). In the study of obese and non-obese children, Okada et al. (2005) found significant relation between plasma PA content and visceral adiposity in obese children.

The fatty acid composition of lipids in serum and muscle is influenced by a diet, a degree of physical activity, and genetic disposition (Vessby 2000). Specific dietary fatty acids may influence the development of diabetes by modifying the PL composition of cell membranes (Boden 1996). The evidence suggests that replacing saturated fats and trans fatty acids with polyunsaturated fatty acids (PUFA) and/or MUFA fats has beneficial effects on insulin sensitivity and is likely to reduce risk of type 2 diabetes (Riserus et al. 2009). A decrease in unsaturated fatty acids was correlated with insulin resistance in childhood obesity (Toledo et al. 
2014). Obese children also showed higher values of DGLA compared to healthy controls in all lipid classes (Decsi et al. 1996).

PA is mostly absent in common diet and is primarily biosynthesized from palmitic acid (16:0) by the stearoyl-CoA desaturase (SCD) in liver and adipose tissue (Paillard et al. 2008). In a genetic mouse model, Cao et al. (2008) suggested that PA released from adipose tissue may serve as a lipokine that mediates the communication between the adipose tissue and other tissues. Stefan et al. (2010) described that the level of PA in serum free fatty acids is a strong predictor of insulin sensitivity in individuals with increased risk of type 2 diabetes. In our study, no significant correlation between PA level and insulin resistance as assessed by HOMA-IR was found.

SCD is an essential and a highly regulated enzyme involved in de novo synthesis of MUFA from SAFA. SCD preferentially converts palmitic acid (16:0) and stearic acid (18:0) into PA (16:1) and oleic acid (18:1) (Enoch et al. 1976). These products are key substrates for synthesis of TG, CE, PL and other kinds of lipids (Paton and Ntambi 2009).

SCD expression is regulated by many dietary and hormonal factors (Ntambi and Miyazaki 2004). High carbohydrate intake and insulin increase SCD gene expression. However, intake of n-3 and n-6 PUFA and leptin inhibit SCD transcription in the liver (Mauvoisin and Mounier 2011). Results from animal and human studies suggest that SCD activity may play an important role in the development of obesity. SCD1-defficent mice have reduced body adiposity and increased insulin sensitivity, and are resistant to diet-induced obesity (Enser 1979, Ntambi et al. 2002). SCD1-deficient mice also have reduced lipid synthesis and enhanced lipid oxidation. Obese people manifest abnormally high activities of SCD in skeletal muscle (Hulver et al. 2005). Okada et al. (2005) showed that SCD activity correlates positively with leptin concentrations but not with serum insulin in obese children. It has also been shown that SCD1 deficiency improves adiposity in leptin-deficient ob/ob mice (Cohen et al. 2002). The results of the study observing dietary and genetic factors influencing fatty acid composition in obese female identical twins suggest that PA may be a metabolic indicator under strong genetic control in humans reflecting endogenous lipogenesis (Kunesova et al. 2002a). In our study, SCD activity together with PA level positively correlated with percentage of body fat. This outcome is in an agreement with previous findings in humans that described an association between SCD activity and PA level on one hand and hypertriglyceridemia, abdominal adiposity, and obesity on the other (Attie et al. 2002, Paillard et al. 2008).

Palmitic acid (16:0) and DGLA are both associated with an unfavorable lipid profile. Dietary palmitic acid is generally regarded as a cholesterol increasing factor, but the results of certain studies have shown only a minor cholesterol raising effect (Hayes and Khosla 1996). Nevertheless, not all of long chained SAFA have the same effect on raising cholesterol level. Myristic acid (14:0) is one of the fatty acids, which increases cholesterol level the most. On the other hand, stearic acid, similarly as oleic and linoleic acid are associated with a favorable lipid profile. PA in plasma PL is independently associated with more favorable HDL cholesterol, total to HDL cholesterol ratio, and fibrinogen, which supports the potential metabolic benefits seen in animal experiments. Conversely, palmitoleate was associated with a higher BMI, greater waist circumference, and elevated TG (Mozaffarian et al. 2010). The effect of PA on TC and LDL cholesterol resembles more the SAFA than MUFA. Our results confirm this finding. However, in addition to increasing levels of TC and LDL cholesterol, also the increase of HDL cholesterol occurs.

In summary, our findings suggest that plasma PA content together with SCD activity is associated with adiposity in obese adolescents. No significant correlation between PA level and insulin resistance was found. PA content in all lipids classes positively correlated with TC, HDL cholesterol, LDL cholesterol levels and TG.

\section{Conflict of Interest}

There is no conflict of interest.

\section{Acknowledgements}

The study was supported by the grants: NT/12342-5 Internal Grant Agency of the Ministry of Health of the Czech Republic.

\section{Abbreviations}

BMI, body mass index; CE, cholesterol esters; DGLA, dihomo- $\gamma$-linoleic acid; MUFA, monounsaturated fatty acids; PA, palmitoleic acid; PL, phospholipids; PUFA, polyunsaturated fatty acids; SAFA, saturated fatty acids; SCD, stearoyl-CoA desaturase; SEM, standard error of the mean; TC, total cholesterol; TG, triglycerides. 


\section{References}

ALDHOON-HAINEROVA I, ZAMRAZILOVA H, ATKINSON RL, DUSATKOVA L, SEDLACKOVA B, HLAVATY P, LEE ZP, KUNESOVA M, HAINER V: Clinical and laboratory characteristics of 1179 Czech adolescents evaluated for antibodies to human adenovirus 36. Int J Obes 38: 285-291, 2014.

ATTIE AD, KRAUSS RM, GRAY-KELLER MP, BROWNLIE A, MIYAZAKI M, KASTELEIN JJ, LUSIS AJ, STALENHOEF AFH, STOEHR JP, HAYDEN MR, NTAMBI JM: Relationship between stearoyl-CoA desaturase activity and plasma triglycerides in human and mouse hypertriglyceridemia. J Lipid Res 43: 18991907, 2002.

BODEN G: Fatty acids and insulin resistance. Diabetes Care 19: 394-395, 1996.

CAO H, GERHOLD K, MAYERS JR, WIEST MM, WATKINS SM, HOTAMISLIGIL GS: Identification of a lipokine, a lipid hormone linking adipose tissue to systemic metabolism. Cell 134: 933-944, 2008.

CARLSON LA: Extraction of lipids from human whole serum and lipoproteins and from rat liver tissue with methylene chloride-methanol: a comparison with extraction with chloroform-methanol. Clin Chim Acta 149: 89-93, 1985.

COHEN P, MIYAZAKI M, SOCCI ND, HAGGE-GREENBERG A, LIEDTKE W, SOUKAS AA, SHARMA R, HUDGINS LC, NTAMBI JM, FRIEDMAN JM: Role for stearoyl-CoA desaturase-1 in leptin-mediated weight loss. Science 297: 240-243, 2002.

DECSI T, MOLNAR D, KOLETZKO B: Long-chain polyunsaturated fatty acids in plasma lipids of obese children. Lipids 31: 305-311, 1996.

ENOCH HG, CATALA A, STRITTMATTER P: Mechanism of rat liver microsomal stearyl-CoA desaturase. Studies of the substrate specificity, enzyme-substrate interactions, and the function of lipid. J Biol Chem 251: 5095-5103, 1976.

ENSER M: The role of insulin in the regulation of stearic acid desaturase activity in liver and adipose tissue from obese-hyperglycaemic (ob/ob) and lean mice. Biochem J 180: 551-558, 1979.

FOLCH J, LEES M, SLOANE STANLEY GH: A simple method for the isolation and purification of total lipides from animal tissues. $J$ Biol Chem 226: 497-509, 1957.

FUKUCHI S, HAMAGUCHI K, SEIKE M, HIMENO K, SAKATA T, YOSHIMATSU H: Role of fatty acid composition in the development of metabolic disorders in sucrose-induced obese rats. Exp Biol Med Maywood NJ 229: 486-493, 2004.

GONG J, CAMPOS H, MCGARVEY S, WU Z, GOLDBERG R, BAYLIN A: Adipose tissue palmitoleic acid and obesity in humans: does it behave as a lipokine? Am J Clin Nutr 93: 186-191, 2011.

HAYES KC, KHOSLA P: Dietary saturated fatty acids and LDL receptor activity. J Nutr 126: 1000-1003, 1996.

HUANG T, WAHLQVIST ML, XU T, XU A, ZHANG A, LI D: Increased plasma n-3 polyunsaturated fatty acid is associated with improved insulin sensitivity in type 2 diabetes in China. Mol Nutr Food Res 54 (Suppl 1): S112-S119, 2010.

HULVER MW, BERGGREN JR, CARPER MJ, MIYAZAKI M, NTAMBI JM, HOFFMAN EP, THYFAULT JP, STEVENS R, DOHM GL, HOUMARD JA, MUOIO DM: Elevated stearoyl-CoA desaturase-1 expression in skeletal muscle contributes to abnormal fatty acid partitioning in obese humans. Cell Metab 2: 251-261, 2005.

IGGMAN D, ARNLOV J, VESSBY B, CEDERHOLM T, SJOGREN P, RISERUS U: Adipose tissue fatty acids and insulin sensitivity in elderly men. Diabetologia 53: 850-857, 2010.

KUNESOVA M, HAINER V, TVRZICKA E, PHINNEY SD, STICH V, PARIZKOVA J, ZAK A, STUNKARD AJ: Assessment of dietary and genetic factors influencing serum and adipose fatty acid composition in obese female identical twins. Lipids 37: 27-32, 2002a.

KUNESOVA M, PHINNEY S, HAINER V, TVRZICKA E, STICH V, PARIZKOVA J, ZAK A, STUNKARD A: The responses of serum and adipose fatty acids to a one-year weight reduction regimen in female obese monozygotic twins. Ann N Y Acad Sci 967: 311-323, $2002 \mathrm{~b}$.

MATTHEWS DR, HOSKER JP, RUDENSKI AS, NAYLOR BA, TREACHER DF, TURNER RC: Homeostasis model assessment: insulin resistance and beta-cell function from fasting plasma glucose and insulin concentrations in man. Diabetologia 28: 412-419, 1985. 
MAUVOISIN D, MOUNIER C: Hormonal and nutritional regulation of SCD1 gene expression. Biochimie 93: 78-86, 2011.

MIYAZAKI M, NTAMBI JM: Role of stearoyl-coenzyme A desaturase in lipid metabolism. Prostaglandins Leukot Essent Fatty Acids 68: 113-121, 2003.

MOLLER DE, KAUFMAN KD: Metabolic syndrome: a clinical and molecular perspective. Annu Rev Med 56: 45-62, 2005.

MOZAFFARIAN D, CAO H, KING IB, LEMAITRE RN, SONG X, SISCOVICK DS, HOTAMISLIGIL GS: Circulating palmitoleic acid and risk of metabolic abnormalities and new-onset diabetes. Am J Clin Nutr 92: 1350-1358, 2010.

NTAMBI JM, MIYAZAKI M: Regulation of stearoyl-CoA desaturases and role in metabolism. Prog Lipid Res 43: 91-104, 2004.

NTAMBI JM, MIYAZAKI M, STOEHR JP, LAN H, KENDZIORSKI CM, YANDELL BS, SONG Y, COHEN P, FRIEDMAN JM, ATTIE AD: Loss of stearoyl-CoA desaturase-1 function protects mice against adiposity. Proc Natl Acad Sci U S A 99: 11482-11486, 2002.

OKADA T, FURUHASHI N, KUROMORI Y, MIYASHITA M, IWATA F, HARADA K: Plasma palmitoleic acid content and obesity in children. Am J Clin Nutr 82: 747-750, 2005.

PAILLARD F, CATHELINE D, DUFF FL, BOURIEL M, DEUGNIER Y, POUCHARD M, DAUBERT J-C, LEGRAND P: Plasma palmitoleic acid, a product of stearoyl-coA desaturase activity, is an independent marker of triglyceridemia and abdominal adiposity. Nutr Metab Cardiovasc Dis 18: 436-440, 2008.

PATON CM, NTAMBI JM: Biochemical and physiological function of stearoyl-CoA desaturase. Am J Physiol Endocrinol Metab 297: E28-E37, 2009.

PELIKANOVA T, KAZDOVA L, CHVOJKOVA S, BASE J: Serum phospholipid fatty acid composition and insulin action in type 2 diabetic patients. Metabolism 50: 1472-1478, 2001.

RISERUS U, WILLETT WC, HU FB: Dietary fats and prevention of type 2 diabetes. Prog Lipid Res 48: 44-51, 2009.

STEFAN N, KANTARTZIS K, CELEBI N, STAIGER H, MACHANN J, SCHICK F, CEGAN A, ELCNEROVA M, SCHLEICHER E, FRITSCHE A, HARING H-U: Circulating palmitoleate strongly and independently predicts insulin sensitivity in humans. Diabetes Care 33: 405-407, 2010.

TOLEDO K, ARANDA M, ASENJO S, SAEZ K, BUSTOS P: Unsaturated fatty acids and insulin resistance in childhood obesity. J Pediatr Endocrinol Metab 27: 503-510, 2014.

VESSBY B: Dietary fat and insulin action in humans. Br J Nutr 83 (Suppl 1): S91-S96, 2000.

VESSBY B, ARO A, SKARFORS E, BERGLUND L, SALMINEN I, LITHELL H: The risk to develop NIDDM is related to the fatty acid composition of the serum cholesterol esters. Diabetes 43: 1353-1357, 1994.

ZAK A, TVRZICKA E, VECKA M, JACHYMOVA M, DUFFKOVA L, STANKOVA B, VAVROVA L, KODYDKOVA J, ZEMAN M: Severity of metabolic syndrome unfavorably influences oxidative stress and fatty acid metabolism in men. Tohoku J Exp Med 212: 359-371, 2007. 